\title{
Possible reduction of cerebral palsy caused by intrapartum fetal hypoxia and in preterm birth
}

\author{
Kazuo Maeda* \\ Department of Obstetrics and Gynecology, Tottori University Medical School, Japan
}

\section{Intrapartum hypoxia index}

Cerebral palsy developed as the sequel of intrapartum hypoxia, the loss of fetal heart rate variability followed by fetal brain damage is rare but important problem among paediatricians and obstetricians. As the author found that intrapartum fetal heart would be damaged by repetition of transient fetal heart rate (FHR) reductions (decelerations), then intended to numerize the deceleration with the hypoxic index (HI), namely, the HI was the sum of decelerating durations (min) divided by the lowest FHR in the decelerations, and multiplied by 100 in the intrapartum fetal heart rate monitoring, because the heart rate is fully parallel to the $\mathrm{PaO}_{2}$ if the $\mathrm{PaO}_{2}$ is lower than $50 \mathrm{mmHg}$ [1], and fetal $\mathrm{PaO}_{2}$ is lower than $50 \mathrm{mmHg}$ [2]. As the hypoxia index was 25 and 26 in the loss of FHR baseline variability, which was the sign of severe fetal brain damage followed by cerebral palsy, whereas normal FHR variability neither followed by fetal brain damage nor cerebral palsy in cases whose hypoxia index was 20 to 24 , where significant difference was found in the development of cerebral palsy among the two groups, it was decided that the lowest limit of hypoxia index to develop cerebral palsy was 25 , where no cerebral palsy was expected to develop cerebral palsy, then the hypoxia index was 24 or less. Thus, a foetus who have any FHR curve changes should deliver the foetus in the stage when the hypoxia index is 24 or less to achieve an infant of no cerebral palsy [3].

\section{Preterm labor}

However, there are neurological sequels in genetic fetal diseases and in preterm birth babies [4]. Although genetic diseases will be treated by chromosomal engineering and gene editing in the future, the strategy to reduce cerebral palsy will be requested to obstetrics and paediatrics.

As the periventricular echo-density (PVE) changed to periventricular leukomalacia (PVL) when fetal PVE was preserved until preterm delivery [4], while there was no PVL in full-term birth baby, the first strategy is tocolysis to prolong pregnancy until full term, while it was failed to prolong pregnancy sedating uterine contraction. As neonatal growth factor disappears 3-4 days after birth, a preterm baby will not receive the shower of maternal growth factor to repair the brain damage in late pregnancy. That will be the reason of PVE preservation and to form PVL in late neonatal stage.

The treatment of neonatal PVE will be the growth factor after ultrasonic detection of neonatal brain PVE. Difficult tocolysis will be related to developmental process of labor contraction, namely, a positive feed-back loop is activated to develop strong oscillation of labor contraction [5], to which common drug tocolysis will be ineffective in preterm birth. Thus, the tocolysis should be performed when the uterine anterior wall is round, uterine cervix is soft and cervical length is shortened in the vaginal scan ultrasound.

\section{Conclusion}

Possible reduction of cerebral palsy was discussed in the birth process and preterm labor.

\section{References}

1. Umezawa J (1975) Studies on the relation between heart rate and $\mathrm{PaO}_{2}$ in hypoxic rabbit: a comparative study for fetal heart rate change in labor. Acta Obstet Gynecol Jpn 28: 1203-1212.

2. Maeda K, Kimura S. Nakano H (1969) Pathophysiology of Fetus. Fukuoka Printing: Fukoka.

3. Maeda K (2014) Modalities of fetal evaluation to detect fetal compromise prior to the development of significant neurological damage. J Obstet Gynaecol Res 40: 20892094. [Crossref]

4. Yamamoto N, Utsu M, Serizawa M, Ohki S, Murakoshi T, et al. (2000) Neonatal periventricular leukomalacia preceded by fetal periventricular echodensity. Fetal Diagn Ther 15: 198-208. [Crossref]

5. Maeda K (2018) Developing process of regular labor contraction. Edelweiss Appli Sci Tech 2: 118-119.
Copyright: (C2018 Maeda K. This is an open-access article distributed under the terms of the Creative Commons Attribution License, which permits unrestricted use, distribution, and reproduction in any medium, provided the original author and source are credited.
Correspondence to: Kazuo Maeda, Department of Obstetrics and Gynecology, Tottori University Medical School, Japan, E-mail: maedak@mocha.ocn.ne.jp

Received: March 07, 2018; Accepted: March 20, 2018; Published: April 05, 2018 